\title{
Pájaros atroces en la novela de la Violencia en el Valle del Cauca ${ }^{1}$
}

\author{
Óscar Osorio \\ Doctor en Literaturas Hispánicas y Luso-Brasileñas \\ Universidad del Valle, Cali, Colombia \\ https://orcid.org/0000-0002-1934-0932 \\ oscar.osorio@.correounivalle.edu.co
}

\section{Resumen}

Las formas del crimen desarrolladas durante la Violencia en Colombia alcanzaron niveles de crueldad inéditas en el país. Poco después de que el Partido Conservador llegara al poder en 1946, amplios sectores del mismo buscaron ampliar sus disminuidas bases políticas mediante la destrucción física y moral del liberalismo. En el Valle del Cauca, algunos dirigentes conservadores constituyeron y financiaron bandas de asesinos que, en asocio con policías y detectives, emprendieron campañas de homogenización conservadora a través tanto del asesinato selectivo como de masacres perpetradas en diversos lugares. Muchos de estos asesinos cometieron sus crímenes con niveles extremos de sadismo y sevicia, ejecutando prácticas oprobiosas sobre las víctimas. De manera que lo atroz se constituyó en una característica fundamental de esta violencia y en un asunto de especial relevancia para la literatura que se ocupó del fenómeno. Examinaré en este trabajo los tipos de asesinos, las formas del crimen y el tratamiento literario de la crueldad en tres novelas vallecaucanas que ficcionalizan la campaña criminal del Partido Conservador en el Valle del Cauca: Viento seco (1953) de Daniel Caicedo, Cóndores no entierran todos los días (1972) de Gustavo Álvarez Gardeazábal, y Noche de pájaros (1984), de Arturo Alape.

Palabras clave: Cóndores no entierran todos los días; literatura y crueldad; Noche de pájaros; novelas vallecaucanas; sadismo y sevicia; Viento seco; violencia en Colombia.

1 Procedencia del artículo: Este artículo es resultado de la investigación "El asesino en la literatura vallecaucana", aprobada en la Universidad del Valle (Cl: 4369). 


\section{Htrocious assassins in the violence novel from Valle del Cauca}

\section{Hbstract}

The methods in which crime developed during la Violence in Colombia reached unprecedented levels of cruelty in the country. Shortly after the Conservative Party came to power in 1946, broad sectors of it sought to expand their diminished political bases through the physical and moral destruction of liberalism. In Valle del Cauca, some conservative leaders constituted and financed gangs of murderers who, in association with policemen and detectives, undertook conservative homogenization campaigns through both selective assassinations and massacres commited in various places. Many of these assassins committed their crimes with extreme levels of sadism and inhumanity, executing opprobrious practices on the victims. Thus, the atrocity became a fundamental characteristic of said violence and a matter of special relevance for the literature that dealt with this phenomenon. In this paper I will examine the types of murderers, the methods of crime and the literary treatment of cruelty in three novels from Valle del Cauca that ficitionalize the criminal campaign of the Conservative Party in Valle del Cauca: Viento seco (1953), Cóndores no entierran todos los días (1972) y Noche de pájaros (1984).

Keywords: Cóndores no entierran todos los días; literature and cruelty; Noche de pájaros, novels From Valle del Cauca; sadism and inhumanity; Viento seco; violence in Colombia.

Recibido: 10 de diciembre del 2019. Aprobado: 02 de marzo del 2020

Artículo de reflexión https://doi.org/10.25100/poligramas.v0i49.8830

¿Cómo citar este artículo en MLA? - How to quote this article in MLA?

Osorio, Óscar. "Pájaros atroces en la novela de la Violencia en el Valle del Cauca." Poligramas 50 (2020): n. pag. Web. Fecha de acceso (día, mes en mayúscula y abreviado, y año).

\section{Contexto socio-histórico}

Aunque no hay acuerdo entre los estudiosos sobre las fechas de comienzo y fin de la Violencia de mediados del siglo XX, se puede aceptar que esta inicia con el ascenso del Partido 
Conservador al poder en 1946 y z un escenario de violencia generalizada que marcaría en sangre y dolor la historia de dos décadas, con cifras que dan cuenta de más de doscientos mil muertos y millones de desplazados viviendo en condiciones de marginalidad en las ciudades. ${ }^{2}$

Según Pécaut, cuatro hechos marcan en el año de 1949 "el rumbo hacia la organización de la violencia": primero, la ruptura de la Unión Nacional; segundo, la decisión liberal de adelantar las elecciones; tercero, la adhesión del Partido Conservador a la candidatura presidencial de Laureano Gómez; cuarto, la decisión del Partido Liberal de no participar en las elecciones y acusar ante el Congreso al presidente Ospina Pérez (Orden... 550). La agudización de la violencia para el año 1949 estaría determinada, entonces, por la coyuntura política relacionada con la necesidad del conservatismo de ampliar sus bases para garantizar su permanencia en el poder. Esta violencia fue ejecutada por miembros de la fuerza pública (detectives y chulavitas) ${ }^{3}$ y grupos parapoliciales, organizados por el Partido Conservador y funcionarios del gobierno:

El factor dominante de los dos primeros gobiernos de la Violencia (1946-1953) fue, pues, el terrorismo oficial ${ }^{4}$ (...) El silenciamiento de la clase obrera ya se había logrado prácticamente desde 1948 y la cruzada antiliberal y anticomunista se convertiría en bandera conservadora a partir de 1949. Para llevarla a cabo, la acción del Estado a través de sus aparatos represivos —como la tenebrosa policía "chulavita" procedente de una región boyacense- es, no suplantada sino complementada con la acción de organizaciones

\footnotetext{
2 Tampoco hay consenso sobre el balance de víctimas fatales de la Violencia. Marco Palacios señala que "quizás nunca sepamos la verdadera cifra de asesinados, lisiados, desposeídos y exiliados. La de 300.000 muertos goza de gran favor en Colombia" (190). Sin embargo, muchos trabajos toman como referencia la de 194.000 muertos consignada por Oquist (1978). El fenómeno fue de tal magnitud que, según Hobsbawn, constituyó "probablemente la mayor movilización armada de campesinos (ya sea como guerrilleros, bandoleros o grupos de autodefensa) en la historia reciente del hemisferio occidental, con la posible excepción de determinados periodos de la Revolución Mexicana" (264-265).

${ }^{3}$ El proceso de conservatización de la policía se consolidó después del 9 de abril de 1948. En el seno de esta nueva policía política se destacaron, por su sectarismo y ferocidad, agentes reclutados en la población de La Uvita en el municipio de Chulavo (Boyacá). De ahí deriva el término chulavita, que identificaba en principio a estos agentes y que luego "se generalizó a la policía que ejercía la violencia, y para los liberales fue un sinónimo de muerte y terror" (Reyes 12). En efecto, las acciones de estos policías asociados con cuadrillas de asesinos, cuya misión consistía en la homogeneización política de sus zonas de influencia a través del exterminio del opositor político, de su desplazamiento o conversión, elaboraron sistemas de destrucción del otro que alcanzaron niveles de degradación inéditos: "Con sus métodos bárbaros y siniestros, los 'chulavitas' implementaron una ruptura real y simbólica tanto del tejido social como del cuerpo humano" (Uribe 97).

4 "Es indiscutible, además, que el gobierno conservador y sus diversos intermediarios locales intervienen activamente en la propagación de la violencia, dirigen las acciones de la policía 'chulavita', se ponen en contacto con los jefes de las bandas de 'pájaros', promueven el clima de terror; en este sentido, la organización vertical de la violencia conservadora precede a su difusión horizontal en las masas campesinas" (Pécaut, Orden... 594).
} 
paramilitares, como los "pájaros" en el Valle y Caldas, los "aplanchadores" en Antioquia y los "penca ancha" en las sabanas de Sucre, cuyas víctimas habrían de contarse por centenares de miles de muertos (Sánchez y Meertens 38).

La mayor intensidad del fenómeno se registró durante los últimos años de la década del cuarenta (1947-1950 $)^{5}$ y, durante este periodo, se desarrolló con especial ferocidad en los departamentos de Antioquia, Caldas, Tolima y Valle del Cauca. En este último, el Directorio Departamental Conservador, bajo la dirección de Nicolás Borrero Olano, dueño del Diario del Pacífico y gobernador desde el 8 de octubre de 1949 hasta el 12 de mayo de 1950, impulsó la creación de guardias cívicas para que, en asocio con las autoridades, ejecutaran "acciones más profesionales, firmes y consecutivas que llevaran a la conservatización del Valle del Cauca y al triunfo electoral de su partido" (Atehortúa 157). Esta campaña en pro de la homogeneización política derivó en una serie de masacres en diversos municipios y pueblos de la cordillera y aún de la capital del Valle:

Según el periódico El Relator de los días 7 y 8 de octubre de 1949: "La tierra en el norte del Valle se ha convertido en tierra sepulcral" a tal punto que ha renunciado el sepulturero de Roldanillo por "sobrecarga de trabajo y que necesitaría dos o tres ayudantes para despachar todos los pedidos..." // Varios incendios de aldeas se señalan, entre ellos el de la Tulia, municipio de Bolívar, y se relatan los éxodos, con columnas de refugiados en los caminos bajando de las laderas del Valle. // Entre el 6 y el 20, se registran, además del incendio de La Tulia, aquel de Naranjal realizado por una columna de 200 hombres, el éxodo de 100 familias de Vijes buscando refugio en Cali y el exterminio total de Betania con un saldo impreciso, el cual posteriormente se establecerá en 260 muertos; también se cuentan un sinnúmero de homicidios simples o múltiples en toda la región y los hospitales no logran recibir a la cantidad de heridos que se presentan diariamente. // Sigue el asalto del martes 18 a la Casa Liberal con saldo de tres muertos y luego el segundo, el sábado 22 que deja tendidos 22 muertos y 50 heridos (Aprile 87-88).

\footnotetext{
${ }^{5}$ En relación con la intensidad de esta primera oleada de violencia, Oquist afirma que "durante los últimos años de la década de 1940 y en particular en 1949, el Estado colombiano fue sometido a un proceso agudo de contracción del poder que llegó a un punto que puede ser descrito como un derrumbe parcial del Estado" (227). Pécaut resalta, estudiando las cifras de Oquist, que (para el periodo 1948-1953) "el total de víctimas representa casi el $1 \%$ de la población" (Orden 551).
} 
En el contexto de esta campaña de homogeneización conservadora a sangre y fuego a través de la policía política y de cuadrillas criminales organizadas por los directorios municipales del Partido Conservador, surge la figura del pájaro: "Como lo hemos venido insistiendo, su origen está íntimamente asociado a la policía política del gobernador Borrero Olano, a las guardias cívicas de los Directorios Conservadores Municipales de los pueblos cordilleranos" (Betancourt y García 105).

El pájaro es un asesino que, al menos en los primeros años, tiene una doble condición: es un asesino a sueldo y un militante del Partido Conservador, esto es, hace del crimen un trabajo y una vocación:

Los "pájaros", organizados en grupos de tres o cinco hombres, fueron utilizados para homogeneizar pueblos, para cambiar conciencias, para convertir a radicales liberales, para perseguir a protestantes, para atacar a masones y comunistas en una "Santa Cruzada" de las "fuerzas del bien" contra las dañinas "fuerzas del mal". Su utilización fue partidista, electoral e ideológica" (Betancourt y García 110).

Los pájaros actuaban en zonas geográficas no muy extensas, incluyendo los pueblos o ciudades donde vivían, y eran financiados y protegidos por organizaciones locales del Partido Conservador, por agentes de diversas instituciones del Estado y por terratenientes que se beneficiaban política y económicamente de sus acciones: "Dirigidos inicialmente por políticos fanáticos del Valle, pronto habrían de caer en manos de todos aquellos en condiciones de apoderarse de las fincas y las cosechas de los liberales" (Palacios 233). Eran certeros y rápidos en la ejecución de los crímenes, que generalmente se cometían contra la población inerme: "Se señala a la víctima, que cae infaliblemente. Su modalidad más próxima es la del sicario" (Guzmán Campos 165).

Rápidamente, los pájaros se constituyeron en referencia del terror y fueron mencionados permanentemente, tanto por su eficacia en la ejecución de asesinatos selectivos como por la ferocidad de su actuar en las muchas masacres que cometieron en asocio con la policía política. Algunos de ellos harían leyenda y la sola mención de sus apodos causaba espanto: "Pájaro Verde (José Manuel Gómez), Pájaro Azul (Manuel Dolores Vélez), El Pajarito (Benjamín García), El Pollo (Gildardo Espinosa), El Buitre (Alfredo Rojas), El Vampiro (Javier Naranjo)" (Atehortúa 158). 
Sobre el terror generado por sus nefandas incursiones se iban tejiendo múltiples relatos que sirvieron de insumo fundamental a la narrativa literaria de la Violencia y que tenían a estos criminales como protagonistas de primer orden. En relación con esto, tres novelas son referencia obligada, no solo para el caso del Valle del Cauca sino de la novela de la Violencia en Colombia: Viento seco (1953), Cóndores no entierran todos los días (1972) y Noche de pájaros (1984).

\section{El relato ficcional de la violencia \\ El Viento seco de la violencia atroz}

Viento seco se publica cuatro años después de ocurridos los hechos que le sirven de referencia en lo real: las masacres de la Casa Liberal y de Ceylán, en octubre de 1949, que fueron perpetradas durante la campaña de conservatización del Valle del Cauca. La visión de mundo del narrador está determinada por una interpretación político-religiosa de la Violencia, que compromete la novela con un proyecto proselitista en favor de la causa de las guerrillas liberales del llano. ${ }^{6}$

En razón de ello, esta ficción narrativa distribuye el mundo según una visión maniquea en la cual los conservadores son malos y los liberales son buenos. Consecuente con esta visión de mundo y con este proyecto político-literario, los conservadores solo aparecen para perpetrar acciones criminales contra los liberales, tienen existencia ficcional en tanto agentes de la destrucción y el mal. ' En palabras de Antonio García, son hombres convertidos en "las bestias más sanguinarias y cobardes" (17).

Con el propósito de mostrar ese talante criminal y poner al lector del lado de la causa liberal, las acciones de los conservadores son relatadas repetida y detalladamente, dando como resultado una sobre exposición y acumulación de escenas de violencia y sevicia: "Pájaro Azul", ratero y asesino de profesión, impuso la tónica. Cayó con saña infernal sobre un hombrazo de acero y le pinchó hasta que sus gritos tuvieron modalidad espectral. El rostro contraído, el llanto y el terror contracturando todos los músculos les satisficieron plenamente. Así sí valía la pena.

\footnotetext{
6 Sustento esta tesis en mi artículo: "Proselitismo y violencia en Viento seco".

7 Con la sola excepción de un acto de bondad de parte del conservador Andrés, quien lleva a los protagonistas (víctimas liberales de la masacre de Ceylán) a Cali y les salva la vida sobornando a la policía con el dinero que obtuvo por la venta de un ganado.
} 
Sobre los otros prisioneros actuaban dos y tres chulavitas. Les cortaban la piel en largas tiras, les amputaban dedos, brazos y piernas, les pinchaban los ojos, les mutilaban la nariz, les arrancaban la lengua, les hendían el vientre con yataganes y machetes y les emasculaban" (70).

Como se trataba de exterminar la presencia liberal, se atacaban zonas relativas a la sexualidad y se mataba a mujeres y niñas para evitar que pudiesen parir más liberales: A la criada y dos niñas las violaron unos veinte policías. Después les enterraron las bayonetas por el sexo y les cortaron los pechos. Como la madre estaba embarazada, le dieron una gran cuchillada en el vientre por la cual salió el feto de seis meses, que pataleaba. Uno se acercó y lo ensartó en el machete... y luego se lo puso en la cara a la agonizante (111).

El narrador concentra buena parte de su relato en ofrecerle al lector una amplia muestra de los procedimientos ejecutados por estos criminales para causar el sufrimiento y la muerte, y las prácticas de profanación de los cadáveres. Una revisión de las formas del crimen presentadas en Viento seco deja el siguiente listado: amedrentamiento e insultos (63, 71, 96, 98, 111); golpes, patadas, cachazos, culetazos, palazos $(63,111,125,135)$; torturas y profanaciones, tales como chuzones $(60,70,128)$, desfiguración $(63,111,127)$, fracturación $(63,128)$, arrastramiento $(64,95)$, azote $(111,127,129)$, arrancamiento de uñas (127), orinar y defecar sobre los cadáveres o hacer comer heces a los agonizantes $(60,66,121,126)$; apuñalamiento y macheteada $(64,70,110,111)$; violaciones individuales y colectivas de niñas y mujeres $(59,60,61,63,73,110,154,179)$; disparos contra la multitud, indiscriminados o a quemarropa $(120,135,151,175,179,183)$ y tiro al blanco sobre las víctimas $(65,129$, 131); aplastamiento (66); extirpación de órganos como la lengua $(58,60,70)$ y el corazón (70, 71); ataque de zonas relativas a la sexualidad femenina, tales como mutilación de senos $(58,61,110)$, apuñalamiento de la vagina $(59,61,110)$, extracción y asesinato del feto (110-111), y en hombres, como la castración y emasculación (58, 60, 70, 111, 131); evisceración $(58,70)$; enucleación de los ojos y cegamiento $(59,60,70,80,111)$; mutilación de la nariz $(60,70)$ y las orejas $(60,128)$; lanzamiento de alturas (100); ahorcamiento (60); ahogamiento $(95,134,135)$; crucifixión (111); empalamiento (60); desollamiento $(61,70)$; quema de personas vivas e incineración de cadáveres $(60,63,64,65,112,179)$; descuartizamiento $(9,60)$; decapitación (79); vampirismo $(65,66)$ y antropofagia (70). 
Muchas de estas acciones criminales se aplicaban progresivamente sobre una misma persona hasta causarle la muerte y continuaban sobre su cadáver. ${ }^{8}$

Los crímenes son perpetrados por tres tipos de criminales conservadores sobre población inerme (179): los policías, los detectives y los pájaros. ${ }^{9}$ Estos aparecen claramente diferenciados en algunos pasajes: "La calle principal de Ceylán, estaba llena de detectives, de policías uniformados y de civiles con armas" (59), "Lamparilla, el jefe de los pájaros, les ordenó a unos detectives y policías que hicieran subir a los detenidos a los camiones" (64), "Los detectives y policías empezaron a caer sobre él" (111), "Algunos detectives y civiles armados salían por las noches a 'cazar rojos'” (116). En otros pasajes, se apela a unos y a otros sin diferenciarlos, de manera que el nombre chulavita o pájaro designa a un asesino del que no se especifica si es policía, pájaro o detective, o, usado en plural, al conjunto compuesto por estos: "Los chulavitas les desfiguraban el rostro" (63), "Otros camiones, automóviles y jeeps repletos de pájaros" (67), "Los chulavitas cayeron sobre estos poblados convertidos a la fe evangélica" (110). También se recurre a varios de estos sustantivos para referirse a un asesino en particular, incluso en el mismo párrafo: "Un chulavita se acercó (...) El forajido le dio un tajo (...) El policía le gritó" (111). Esto se complementa con el uso de otras expresiones identificadoras del criminal conservador sin discriminar a qué organización pertenece: bandoleros (64), chacales (69), forajido (111). La intencionada estrategia de discriminar a los asesinos conservadores según la organización a la que pertenecen y luego trocar o mezclar sus apelativos de tal suerte que no solo no sea posible tal clasificación parece obedecer a una intención autorial de hacer que el lector perciba a esta variopinta y nutrida red de asesinos como una sola entidad, un solo cuerpo del mal destruyendo como un viento seco (pensaría el autor) la vida liberal.

\footnotetext{
8 Pineda Botero señala que "la obra se presenta como un catálogo de las distintas formas de tortura, violación y muerte" (123).

${ }^{9}$ La tercera parte de la novela da cuenta de los enfrentamientos entre la policía y grupos de resistencia liberal conformados por víctimas sobrevivientes. Sin embargo, estos guerrilleros liberales no ejecutan los crímenes con sevicia. Están desprovistos, pues, de la maldad y el sadismo en los que se regodean los conservadores. Esto se explica por el carácter maniqueo de la novela y porque estos grupos de resistencia apenas se estaban conformando en el período al que remite la diégesis. La degradación en las formas del crimen fue un proceso desarrollado en el tiempo: "En el proceso de la violencia la forma del crimen marca una parábola progresiva hacia la atrocidad y el sadismo. En este terreno no se puede generalizar ni sobre los autores ni sobre las regiones. Comprometidos aparecen elementos del ejército y la policía, guerrilleros, pájaros y bandoleros" (Guzmán Campos 225). Al cabo de muy pocos años unos y otros fueron igualmente sádicos en sus rituales de muerte.
} 
Además de hacer evidente el sadismo como una constante en todas las formas del crimen, el narrador insiste en indicar la condición sádica del asesino conservador, en explicitar el goce que este siente en la destrucción del otro: "Los gritos le causaban satisfacción [Descuartizador]" (60), "El asesino [Vampiro] tuvo un fulgor destellante en la mirada" (66), "El rostro contraído, el llanto y el terror contracturando todos los músculos le [Pájaro Azul] satisficieron plenamente" (70), "Los polizontes [policía], cumplida su tarea, quedaron sudorosos y contentos" (126), "Y eran felices [detectives] y sentían erotismo sádico con el dolor humano" (130), "Cuando los agentes de la Seguridad [detectives] le hubieron castrado, se sentaron complacidos" (131). Esta satisfacción en el crimen define a esa entidad criminal conservadora (policía-detectivepájaro) y el texto abunda en escenas en las cuales se repiten frases como las citadas y descripciones detalladas de rituales criminales que dan cuenta de este placer sádico. De esta manera, se traza la imagen del asesino conservador durante la campaña de conservatización del año 49 en el Valle del Cauca.

Con la acumulación y repetición de escenas cruentas en las que se desarrollan las formas del crimen y las prácticas atroces que caracterizaron la Violencia, y la explicitación de características oprobiosas en la descripción de los criminales, Caicedo logra, como otros novelistas del fenómeno, "ponerles los pelos de punta a sus semejantes" (García Márquez 287). Esta estrategia narrativa tiene una doble consecuencia: en primer lugar, logra generar una censura sobre el proceder de los conservadores y una simpatía o, al menos, una justificación para la reacción armada liberal; en segundo lugar, le atrae una sanción negativa sobre el valor literario de su creación.

\section{Noche de pájaros en carros fantasmas}

La masacre de la Casa Liberal ocurrió en Cali el 22 de octubre de 1949. Rápidamente, se publicó una "versión oficial" por parte de la Gobernación del Valle del Cauca que trató de tergiversar los hechos: "El saldo de veintidós muertos y cincuenta heridos fue explicado públicamente por el gobernador Borrero Olano como "producto de ataque de una banda de liberales al cuartel de la policía"' (Atehortúa 169).

Sin embargo, la verdad histórica se impuso y los relatos sobre estos sucesos coinciden en lo fundamental: se trató de una masacre ejecutada por agentes de seguridad del Estado contra población inerme: 
La casa se convirtió en el punto culminante del éxodo creado por las acciones de los pájaros en todo el Valle. Hombres, mujeres y niños cuya única propiedad era la vida en medio de una profunda tristeza. El 18 de octubre llegaron hasta ellos cincuenta agentes de policía decomisando cédulas, dinero y hasta algunas aves que las familias tenían consigo. Cuatro días más tarde, un grueso grupo salido de las oficinas del detectivismo se apostó a la salida de la sede liberal y disparó sin piedad contra la muchedumbre. El ejército, al mando de Rojas Pinilla, llegó a detener y a torturar a los sobrevivientes (Atehortúa 169).

Noche de pájaros de Arturo Álape tiene como referencia histórica fundamental esta masacre, pero solo dedica unas pocas páginas (84-90) a esos hechos. En lo fundamental, el relato de la novela coincide con el histórico: Algo le llamó la atención, no precisamente por el grupo de hombres que apareció de repente, sino por la forma en que disfrazaban sus rostros. Se alarmó porque entraron en tropel y armados. Usted pensó que eran de los mismos, quizá una guardia cívica, en fin, esa era su explicación. Luego descubrió que estaba equivocado, no podría precisar cuántos eran, pero había rabia en ellos: calados los sombreros hasta las cejas y los revólveres en las manos coparon la entrada abierta al patio y ese grupo uniforme, comenzó a moverse como arena movediza, meticulosamente cada uno a su puesto, produciendo en usted un terror inexplicable. La razón vino a sus ojos como una astilla. Los hombres ensombrerados disparaban ahora a un fácil blanco localizado en esa masa inerme, apeñuscada, resignada $(86){ }^{10}$

El actor focalizado a través del cual el narrador da cuenta de los hechos es un empleado que ve la masacre desde la ventana de su oficina. La narración se hace en segunda persona y el testigo es referido permanentemente por el narrador con el pronombre de la segunda persona del singular sin que se devele su identidad: "Usted se sorprende" (10). Toda la historia está construida en función de las experiencias del testigo protagonista cuya vida se destruye con la masacre de la Casa Liberal. Él no tenía ninguna relación con los liberales allí refugiados ni con

\footnotetext{
10 Esta masacre es el otro gran hito de la violencia conservadora en Viento seco y su relato de estos hechos coincide plenamente con el de Noche de pájaros. los asesinos del gobierno actúan encubiertos: "Sombreros calados hasta las cejas y pañuelos anudados al cuello, listos para cubrir sus caras con antifaces" (Caicedo119); los asesinos se limitan a disparar sobre sus víctimas buscando eficacia en el número de muertos sin incurrir en prácticas de sevicia y sadismo: "Los agentes vaciaban sus armas y volvían a cargarlas serenamente. Hubo quien repitió la maniobra de recarga cinco veces" (120). Aunque en la novela de Caicedo el relato de la masacre se atiene a estos hechos, cuando el narrador cuenta sobre lo ocurrido posteriormente con los sobrevivientes que tomaron prisioneros se despliega de nuevo el sadismo y la sevicia de policías y detectives.
} 
los detectives que los atacan. Sin embargo, el azar lo sitúa en el lugar y el tiempo que lo convertirán en testigo de lo ocurrido y que a la postre lo convertiría en víctima de esos asesinos.

La diégesis se concentra, entonces, en las peripecias del testigo protagonista durante los días posteriores a la masacre, después de haber visto su foto en el Diario del Pacífico (de propiedad del gobernador Borrero Olano) donde se informaba que él era el único testigo, "el hombre que podría señalar a los culpables de todo lo que había visto esa tarde y esa noche, en el patio de esa casona" (16). Él sabe que esa noticia es una condena a muerte y, sin atreverse a regresar a casa, deambula por la ciudad tratando de evitar que los asesinos del gobierno lo encuentren. En el transcurso de esas noches azarosas, recuerda los sucesos de la Casa Liberal (antes, durante y después de la masacre) y los sucesos de su vida: su infancia, su familia, la muerte de sus hermanos, la primera experiencia sexual, su crecimiento, su deambular por la ciudad, su matrimonio) y los días previos a su muerte, acechado por la violencia que atenaza a los pobladores de la ciudad.

Como el proyecto narrativo de Noche de pájaros consiste en una inmersión en la figura de la víctima, el relato de su vida ocupa la mayor parte de la novela y los sucesos relativos a la Violencia priorizan sus efectos sobre el testigo protagonista. Es por eso que la novela se abre y se cierra con los atentados que este sufre durante el itinerario de su huida: los dos primeros renglones narran el primer atentado: "La calle cicatrizada doblemente por la violenta frenada del carro grande y negro y, ante el impacto que lo abruma al sentirlo tan cerca, usted se sorprende como si recibiera el primer golpe" (9); el penúltimo párrafo narra su asesinato: "Se detienen un poco, abren las ventanillas y disparan los revólveres sobre su espalda en puntería que no perdona. Usted queda sostenido en la agonía, al final lo empuja la muerte y cae al suelo de bruces sobre sus narices" (102).

En lo atinente a la historia relativa a la Violencia, Noche de pájaros se ocupa, más que de la masacre (5 de 103 páginas), de dejar constancia del ambiente de zozobra que agobia al testigo y a la ciudad, antes y después de esos sucesos. A la construcción de este ambiente contribuye la reiteración de dos hechos: el toque de queda a partir de las siete de la noche (12, 27, 27-28, 78) y el deambular de "carros fantasmas" infestados de criminales del gobierno que van por las calles de la ciudad asesinando transeúntes $(9,10,11,14,17,25-27,32,35$, $63,69,74,101,102)$. 
El toque de queda es una decisión gubernamental, que tiene efectos inmediatos en la percepción que los habitantes tienen de su entorno: "Cali, imagen de volcán desolado desde cuando se implantó el toque de queda a las siete de la noche" (12), "Daba la impresión de que Cali vivía dos vidas. La ciudad aparentemente libre, alegre y bulliciosa que ansiaba con pasión el fútbol en los fines de semana. Y la otra, la de la noche que discurría bajo un velo que todo lo ocultaba. Nadie sabía nada, nadie indagaba por los desaparecidos" (27-28). Es precisamente en esa ciudad desolada por el toque de queda donde los asesinos del gobierno pueden ejecutar sus crímenes sin mayor oposición. El toque de queda procura las condiciones favorables para el accionar de los criminales y los autos negros de vidrios oscuros lo que hace posible su movilidad y eficacia: Carros grandes, negros, americanos, de gran cilindraje, de potente motor, consumidores compulsivos de gasolina, altos y de fuertes guardachoques para atropellar una casa, con el peso de sus dos toneladas; forrados en latas de hierro, vidrios pequeños y divididos en dos mitades, ventanas oscuras, con sus hombres a bordo, cuatro adelante, cuatro atrás, que sentados cómodamente pueden ver la vida que transcurre en las calles y visualizar cualquier objetivo que ande o corra (101-102).

Los "carros fantasmas" causan espanto por los criminales que en ellos se desplazan y por las muertes que dejan a su paso. El narrador no ofrece muchos datos que permitan una caracterización sólida de este tipo criminal porque está enfocado en la figura de la víctima, el testigo que sufre el despojo de todo lo que constituía su vida, su desvanecimiento interior, su desasosiego y su muerte.

Sobre los criminales se dice, básicamente, que ocultan su identidad en la bruma de la noche, con medias o sombreros en sus cabezas o tras los vidrios polarizados $(10,12,26,86)$, que se satisfacen en el crimen $(14,26,87)$ y están embriagados de alcohol y poder (26). También se señala la vinculación institucional de estos asesinos: "No existen para ellos, hombres carnetizados por la Gobernación del Valle y de profesión sicarios, armados por el directorio conservador, tales nimios inconvenientes. Son los dueños de las noches de Cali" (26).

Aunque no se usa el nombre "pájaro" (salvo en el título) para designar a estos criminales, el narrador acude a una serie de imágenes estructuradas sobre la relación asesinos-pájaros para referirse a ellos $(11,26,32,35)$ : No huye de los hombres, de los carros negros, huye de sus pasos agigantados sobre las espaldas, huye al sentirse pisado por sus pies. Y corre viendo a un pájaro que vuela sin vaivenes, que ahuyenta la noche al explayar sus alas, que rebasa la 
nube más alta y se impulsa en picada y viene sobre su cabeza, diminuta desde el aire, sosteniendo en su pico un revólver calibre 38, que dispara sin compasión sobre su cerebro, y como vidrio que se astilla, brota sangre coagulada en esquirlas que chocan contra las paredes de las casas que se desploman (32).

Con estas imágenes y con el breve relato de la masacre de la Casa Liberal, Noche de pájaros establece el contexto del accionar del testigo protagonista que, en el desarrollo de su periplo por la ciudad, va dejando constancia de la violencia a la cual el Estado, a través de sus asesinos, somete a la población. Es, entonces, una novela sobre el miedo que la violencia partidista provoca en el tejido social y sobre la responsabilidad del gobierno en la organización de esta violencia.

\section{Cóndores no entierran todos los días y la verdad histórica}

Cóndores no entierran todos los días (1972) se publica casi veinte años después de Viento seco y doce años antes de Noche de pájaros. Su eje narrativo se construye sobre la figura de León María Lozano, actor protagonista sobre quien se hace una inmersión en dos dimensiones fundamentales: su historia íntima y familiar (desde 1926, cuando empieza a trabajar en la librería de Marcial Gardeazábal, hasta su muerte en noviembre de 1958), y su historia criminal (desde su conversión en el Cóndor, algunos meses después de su defensa del Colegio de los Salesianos el 9 de abril de 1948, hasta su muerte). La novela indaga, en la primera dimensión, la condición humana del personaje en lo atinente tanto a su filiación ideológico-religiosa como a sus relaciones afectivas, familiares y sociales; en la segunda, da cuenta de la figura histórica del jefe de los pájaros del norte del Valle del Cauca en lo concerniente a los crímenes perpetrados bajo sus órdenes.

En lo que se refiere a la primera dimensión, el relato es prolífico y repetitivo en mostrar, describir y señalar las características de León María Lozano: honrado: "Fue el primer y el único documento que León María falsificó en su vida" (24); agradecido: "El siguiente lunes le envió un cuajo completo a don Marcial, empezando así una costumbre de gratitud que no interrumpió ni en los momentos más altos de su vida" (25-26); devoto: "Uno de los más piadosos varones de la parroquia" (28-29); conservador sectario: "No compraba ni leía otro periódico [ El Siglo], ni dejaba oír otra emisora que La Voz Católica. Todo lo demás, o no era conservador o no era católico y ni a él ni a su familia le podían interesar" (58); supersticioso: "Le hizo creer que de 
verdad le había llegado la hora, pronosticada tiempo atrás por el lego de Palmira"(39); discreto: "No le gustaban los escándalos ni las fiestas" (49); celoso: "Las llegó a querer tanto [a sus hijas] que no le permitió nunca a Amapola, la mayor, que se le arrimara algún hombre" (42), "Siempre vivió celando de ella [Agripina, su esposa]" (53).

El relato también construye una serie de oposiciones relativas a la configuración del personaje protagonista: "[Tenía] una noción de poder que nunca más la volvió a perder" (13), pero era enfermizo y asmático: "Desde que tenía siete años comenzó su martirio" (37); era el jefe de los asesinos: "Quien dirigía toda esta matazón era León María Lozano" (92), pero "jamás había disparado alguna [arma], nunca se le vio cargando ni manejando una" (36); era un "católico ejemplar" (30), pero sus hijas nacen de una relación por fuera del matrimonio; maneja las finanzas de la organización: "Su exigua cuenta del banco resultó con una consignación imposible de hacer con la venta de quesos en un mes" (76), pero vive y muere pobre porque no usa en beneficio propio los dineros que le son asignados para la campaña criminal: "León María, aunque pudo haberse vuelto más rico que todos ellos [los ricos del pueblo], jamás compró una plaza de tierra ni obligó a nadie a vendérsela" (97) y "cuando fue a pagar los aguardientes no tenía un centavo (160). ${ }^{11}$

La figura de León María Lozano se construye, entonces, con unos rasgos bien definidos: radicalismo político y religioso (que lo conduce al crimen), lealtad, honradez y sentido de familia. ${ }^{12}$ La caracterización del personaje remarcando sus rasgos definitorios y sometiéndolos a ese sistema de oposiciones tiene el propósito de dotar al personaje de una complejidad que garantice su dignidad literaria. ${ }^{13}$

En cuanto a la segunda dimensión, queda bien establecido su rol como jefe de los pájaros y su papel preponderante en la campaña de exterminio que dejó "tres mil quinientos sesenta y

\footnotetext{
${ }^{11}$ Carmiña Navia señala que "León María Lozano, actor principal de la novela Cóndores no entierran todos los días se constituyó en un asesino no por su propio interés personal sino única y exclusivamente por sus 'ideales políticos' de católico conservador" (106).

12 Los celos a la esposa y las hijas son inherentes a una noción de amor construida en el marco de una visión conservadora, provinciana y machista; de igual manera, el sentido de lealtad y de honradez en este asesino se explica por el modelo de interacción social que determina su axiología. La conclusión de Carmiña Navia, en su artículo sobre la construcción del héroe en Cóndores no entierran todos los días, va en ese sentido: "León María Lozano es producto del cruce de una serie de contradicciones y fuerzas políticas, económicas, sociales y religiosas" (106).

${ }^{13}$ En "La novelística de la violencia en Colombia", Álvarez Gardeazábal define a estos asesinos como "personajes de leyenda" (97) y afirma que esta condición debe ser aprovechada para construir personajes consolidados literariamente.
} 
nueve muertos de la violencia que fueron enterrados en el cementerio de Tuluá" (158). La novela desarrolla el proceso de constitución de la figura del Cóndor en una secuencia bien definida de acciones que lo llevan desde su anónima posición como vendedor de quesos de la plaza de mercado de Tuluá hasta el lugar destacado que ocupó como líder indiscutible de las bandas de asesinos del norte del Valle. La primera acción que lo proyecta hacia esa condición ocurrió durante los sucesos violentos que se desarrollaron en respuesta a la muerte de Jorge Eliécer Gaitán, el 9 de abril de 1948, "cuando se opuso, con tres hombres armados con carabinas sin munición, un taco de dinamita que llevaba en la mano y una noción de poder que nunca más la volvió a perder, a que la turba incendiara el colegio de los salesianos" (13). Esta acción lo hace visible para la dirigencia conservadora, que lo escogerá como el líder asesino de la campaña de conservatización del Valle del Cauca: "Los tres doctores [Navia, Olano y Ramírez Moreno] terminaron seguramente de darle los grandes designios a León María y lo dejaron en su casa con las tres cajas de carabinas al tiempo que le prometían unas ametralladoras recortadas para la semana siguiente" (70). Entonces, "aparecieron los primeros muertos en las calles" (73) y "comenzaron los chismes sobre León María" (76). Tres meses después, en febrero de 1950, durante el asalto a Río Frío, "León María Lozano se identificó como el jefe de la banda asesina" (92). Sin embargo, "Tuluá tuvo que traumatizarse para poder convencerse de que quien dirigía toda esta matazón era León María Lozano" (92), el mismo que "manejó con el dedo meñique a todo el Valle y se tornó en el jefe de un ejército de enruanados, sin disciplina distinta a la del aguardiente, motorizados y con el único ideal de acabar con cuanta cédula liberal encontraran en su camino" (94-95). Luego vendrá su declive, el cambio de gobierno en 1957 y su muerte en 1958.

El narrador deja claro que quienes organizaron, instrumentaron y financiaron la violencia fueron los dirigentes conservadores y que lo hicieron con el objetivo de convertirse en mayoría política y mantener el poder: "Navia y Olano también lo advirtieron desde su sede conservadora y armaron la rebelión (...) Los conservadores del Valle del Cauca formaron ellos mismos su propia policía privada y le dieron funciones específicas con miras a las elecciones presidenciales" (66). También señala que los pájaros actúan en asocio con las fuerzas de seguridad del Estado 
y con el gobierno: "El gobierno era algo igual a los pájaros y los pájaros eran algo igual al gobierno" (137) $\cdot^{14}$

En cuanto a la dinámica violenta y las formas del crimen, las masacres de 1949 son referidas a partir de los muertos que los criminales traen de las montañas y dejan tirados en las calles de Tuluá: "En todas las cuadras de Tuluá, menos en la del colegio y en la de León María Lozano, tuvo que entregar [el sacerdote] la bendición a un cadáver" (82).

Precisa el narrador, haciendo referencia a estos hechos, que "todos tenían la herida de bala en la nuca y estaban bien muertos (...) Ninguno tenía muestras de otra herida" (82-83). El narrador insiste durante buena parte del relato en que esas ejecuciones se hacían con un tiro en la nuca sobre hombres mayores y no había evidencia de tortura $(12,73,75,82,83,99)$.

Solo en la última parte de la novela y cuando han pasado más de tres años del periplo criminal del Cóndor, el narrador nos dice que "a Ceilán le habían echado candela por los cuatro costados los pájaros que acaudillaba León María Lozano" (102). Desplaza esta masacre al 23 de octubre de 1952 (101), tres años después de su ocurrencia histórica ${ }^{15}$ y nos dice, entre paréntesis, que "después de la matanza de Ceilán ya no bastó con el disparo en la nuca, sino que los empezaron a machetear" (105). Algunas páginas adelante nos relatan que al hijo del maestro Cedeño lo habían castrado (118), asesinato con el cual se inicia la masacre de 249

\footnotetext{
${ }^{14}$ Las tres novelas estudiadas en este trabajo parecieran compartir dos propósitos: uno, dejar constancia de unos hechos tergiversados por la verdad oficial y la censura; dos, señalar la responsabilidad de esa violencia en el gobierno y los directorios departamentales y municipales del Partido Conservador, con la complicidad de la policía y el detectivismo.

${ }^{15}$ Este desplazamiento temporal no es un descuido y no se puede adjudicar a desconocimiento del autor, pues Álvarez Gardeazábal conocía bastante bien estos hechos y sabía de su importancia histórica, no solo por su investigación para la novela sino porque la primera parte de su monografía de grado es un capítulo dedicado al fenómeno de la violencia, en el cual habla del proceso de conservatización del Valle y hace varias referencias a sucesos de Ceylán y de la Casa Liberal, que considera "los más dantescos de este periodo" (La novelística... 14). Además, esta masacre es relatada por el autor en uno de sus cuentos: "Ana Joaquina Torrentes". Como esta, hay otras imprecisiones cronológicas, que Jacques Gilard explica porque "esta historia contemporánea entra más bien en el molde arcaico del relato trágico, y ello se debe a la utilización de un discurso narrativo muy alejado de las actitudes históricas" (74). Conclusión que evidentemente no comparto, ni comparte Álvarez Gardeazábal, como se verá más adelante. Sin embargo, es necesario reconocer que la novela tiene inconsistencias cronológicas, no solo en relación con el fenómeno histórico sino en lo atinente a su propia diégesis. Una muestra: la muerte de Rosendo Zapata se sitúa el 22 de octubre de 1949 (12) y con este crimen abre la novela porque lo considera "el primer muerto oficial" (12). Luego nos dice que el 23 de octubre de 1952, "dos años exactos después de la muerte de Rosendo Zapata" (101), El Relator dio la noticia de la masacre de Ceylán. Hay una evidente inconsistencia en la cronología, pues entre 1949 y 1952 transcurren tres años, no dos, y hay una imprecisión histórica porque la masacre de Ceylán ocurre el 27 de octubre de 1949. La masacre que tuvo lugar el 22 de octubre, el día en el cual el narrador nos dice que mataron a Rosendo Zapata, fue la de la Casa Liberal en Cali.
} 
personas (120) realizada durante los doce días que duró la venganza del Cóndor contra Tuluá por haber celebrado la falsa noticia de su muerte.

Según esto, la castración como práctica criminal aparece solo durante el ejercicio de la venganza personal del Cóndor y no durante las acciones armadas determinadas por sus convicciones político-religiosas. Además, el narrador asevera que estas masacres se perpetraban solamente contra hombres adultos, pues el jefe de los pájaros no admitía el crimen contra mujer: "No podía perdonar que sus hombres mataran una mujer y si alguna vez alguien lo hizo, él mismo se encargó de entregarlo al batallón Palacé con las pruebas del asesinato" (128). Tampoco se hace referencia alguna al crimen contra menores de edad o al sadismo en las ejecuciones hasta casi el final de la novela:

Los muertos siguieron creciendo y el sadismo empezó a aparecer en las matanzas. Cuando mataron a los del Recreo, todos creyeron que eran liberales los asesinos porque entre los muertos había tres mujeres mayores y once niños, pero Tobías Arango era liberal, aunque les pagaba cuotas a los Rojas desde los primeros días y en los días siguientes los muertos no fueron solamente hombres (139).

Sin embargo, el narrador deja claro que estas masacres no solamente no son ordenadas por el Cóndor, sino que para esa época ya había perdido el control de los pájaros y es cuando él se da "cuenta que su poder había menguado y que lo que inicialmente manejaba desde la mesa del Happy Bar ya no estaba sino nominalmente bajo su dominio" (139).

El narrador deja establecido, entonces, que bajo el control del Cóndor, Tuluá y las zonas cordilleranas vivieron una violencia de gran intensidad que se medía en miles de muertos. Sin embargo, insiste en que esta violencia se ejecutaba con eficaces tiros en la nuca sobre hombres adultos, que no se ejercía sobre mujeres ni sobre niños y que no había sevicia contra las víctimas. Nos dice el narrador que es mucho después, una vez que el Cóndor envejece y pierde control sobre algunos jefes de sus cuadrillas de pájaros, cuando la violencia se desboca hacia el sadismo.

Ahora bien, este relato ficcional se estructura en función de la pretensión autorial de ofrecer la verdad verdadera sobre esos hechos, como queda consignado en la "aclaración necesaria" que sive de prólogo a la edición de Plaza y Janés de 1984: "Puse para siempre en las letras de un libro la historia que se le ha ido olvidando a la patria convencido que con ella 
podría evitar repeticiones inútiles" (8). ${ }^{16}$ La decisión de dejar "para siempre" en letras de molde el registro de los hechos históricos es tomada, según el autor, con el propósito de dejar una lección que impida la repetición de esos hechos de violencia.

Para ello, el autor recurre a un procedimiento textual que consiste en la oposición recurrente entre la verdad del narrador y las versiones falsas o inexactas de una especie de entidad desmemoriada llamada Tuluá: "Tuluá no lo sabe porque su memoria se acerca mucho a la de una gallina. Por eso no pueden saber exactamente cuándo empezó su martirio" (78). ${ }^{17}$ Dicha verdad está garantizada porque esa imagen del hecho histórico, dice el autor en la "aclaración necesaria", es el resultado de su propia experiencia, de la de las víctimas y la de los victimarios: Escribí Cóndores como una novela. Surgió de la vivencia infernal de mi infancia en las calles de Tuluá, en pleno rigor de la violencia política que azotaba a Colombia entonces. Los personajes que en ella circulan no son más que el fruto de una observación novelística, así tengan es estas páginas los nombres con los cuales aporrearon las calles de Tuluá o se escondieron para siempre en las tumbas del cementerio como protagonistas del momento (7).

Según la explícita pretensión de autor, esa verdad del narrador "es la verdadera historia" (8). Así las cosas, esta verdad nos sitúa frente a una violencia dirigida por un fanático religioso y político, honesto, celoso de su familia, buen vecino, leal y agradecido, que no usó ni portó un

\footnotetext{
${ }^{16} \mathrm{El}$ análisis de la novela que hace Gilard contradice estas afirmaciones del autor. Nos dice el crítico para desestimar la vocación de verdad histórica de la novela que "no hay que pedirle perlas al olmo" (66). En la misma dirección que Gilard y, por lo tanto, en contravía de la valoración misma que Álvarez Gardeazábal le da a su novela en tanto su condición de verdad y memoria, Maite Villoria Nolla propone el estatuto "fictual" de la novela: "Es obvio que Cóndores... no pretende situarse como discurso verdadero o falso y, por ello, no podemos atrapar a la novela en un marco polarista que base sus discusiones en la mono-referencialidad del texto, reduciendo a la prosa narrativa en dos modos de narración —como texto factual o ficticio- sino que se debe analizar a partir de la combinación de ambos conceptos" (230).

17 Una de las razones de esta desmemoria se funda en la censura de prensa que restringía la comunicación de los hechos (101) y los reducía a chismes de vecinos. Álvarez Gardeazábal afirma que las masacres de Ceylán y la Casa Liberal eran "temas vedados para la prensa de ese entonces" ("La novelística" 55). La censura de prensa provoca que la memoria de esos hechos se construya a través de microrelatos de sobrevivientes y testigos que se van transformando en su repetición, que se van convirtiendo en versiones distorsionadas. Cóndores no entierran todos los días se construye en la estructura discursiva del chisme, que es una representación de ese entramado de microrelatos cuya fidelidad a los hechos se ha perdido. Pécaut sostiene que "el chisme tiene el mismo estatuto que los micro-relatos. Remite a puntos de vista que no pueden ser ni sustentados ni comunicados entre sí. De ello resulta una asombrosa ausencia de memoria colectiva" (Reflexiones... 67). En este sentido, Laura Restrepo interpreta las consecuencias de esta propuesta narrativa en Cóndores no entierran todos los días: "Manejando hábilmente este juego de informaciones, quizás verídicas, quizá falsas y distorsionadas, el autor refunde la realidad en el laberinto verbal de los comadreos de provincia, de tal manera que la novela no presenta en primer plano la historia objetiva, sino la historia interior y mítica que se gesta en las murmuraciones y se alimenta de los decires" (153). Es precisamente a esas versiones falsas sobre los hechos acaecidos que el narrador (y el autor en su "aclaración" lo ratifica) opone la versión verdadera de su relato.
} 
arma jamás en su vida y que con una noción de poder extraordinaria logró por más de tres años que esa violencia se ejecutara sin sadismo y sólo contra hombres mayores.

Este relato se sitúa en las antípodas del relato de Viento seco, que es considerado (incluso por el mismo Álvarez Gardeazábal) como un testimonio de enorme valor documental. También va en contravía del relato histórico, según el cual esta violencia fue perpetrada con altos índices de crueldad desde su agudización en 1949: Entre 1949 y 1953, la policía "chulavita" llevó a cabo numerosas masacres que se caracterizaron por su sevicia y crueldad. De esta manera inauguraron una serie de prácticas atroces que serían adoptadas por los bandoleros liberales y conservadores. La policía "chulavita" inauguró un inventario de cortes realizados con machete que transformaron profundamente la morfología del cuerpo humano. Dentro de las tácticas utilizadas por estos policías para intimidar y aterrorizar a los campesinos Liberales y a los comunistas se pueden mencionar el chantaje, las golpizas públicas con la parte plana del machete, conocidas como "aplanchadas", los cortes y mutilaciones corporales, el incendio de casas, parcelas y animales domésticos y los mensajes anónimos amenazantes. Con sus métodos bárbaros y siniestros, los "chulavitas" implementaron una ruptura real y simbólica tanto del tejido social como del cuerpo humano (Uribe 97).

El relato de la campaña de conservatización del Valle del Cauca en Cóndores no entierran todos los días se construye entonces sobre una profunda distorsión del hecho histórico, en lo atinente al desplazamiento cronológico de la masacre de Ceylán y a su característica definitoria: la crueldad y la sevicia en los crímenes ejecutados sobre hombres, mujeres y niños.

La decisión de hacer esta distorsión histórica parece deberse a consideraciones estéticas. Efectivamente, uno de los elementos fundamentales de la novelística de la Violencia en Colombia es la compleja relación entre el hecho histórico y el estatuto literario del texto. ${ }^{18}$ Los autores y autoras se enfrentaron a una violencia especialmente atroz y las decisiones sobre las formas de representarla definieron su valor literario. Escritores como Daniel Caicedo optaron por el registro descarnado de las diversas formas del crimen y produjeron novelas en las cuales la acumulación y repetición de estas acciones oprobiosas y del carácter sádico de sus ejecutores las deslegitimó como obras literarias; otros, como Álape y Álvarez Gardeazábal, buscaron otros caminos.

\footnotetext{
${ }^{18}$ En mi artículo "Siete estudios sobre novela de la violencia en Colombia, una evaluación crítica y una nueva perspectiva" examino este asunto.
} 
Álvarez Gardeazábal conocía muy bien la novela de la Violencia porque en su trabajo de grado para obtener su título en Letras en la Universidad del Valle estudió ese corpus. En dicha monografía examinó más de cuarenta obras y señaló, entre muchas otras falencias, que una buena parte de esta literatura no se consolidaba literariamente por esa subordinación a la realidad: "Parece como si todos estuvieran desesperados por rendir un testimonio generacional y no enfrentándose a una posibilidad literaria de incalculables amplitudes" (La novelística... 16). De hecho, en el apartado dedicado a Viento seco, el monografista señala que es una mala novela por dos razones fundamentales: la primera, por ese exceso en el detalle de la sevicia y el sadismo: "Es una recolección de detalles mínimos de la más absoluta crudeza" (56); la segunda, por la falta de profundidad del personaje protagonista: "Antonio Gallardo, el personaje central, no alcanza a mostrarse en ninguna ocasión como un personaje consolidado" (56). ${ }^{19}$

Álvarez Gardeazábal escribe esa monografía dos años antes de la publicación de Cóndores no entierran todos los días y es evidente que la novela constituye la respuesta a lo que él consideró la falla principal de Viento seco y la falencia general de esa novelística de la Violencia. Dicha respuesta es la construcción de un personaje consolidado ("de leyenda") y la elusión de "la crudeza" y la sevicia en lo atinente a las formas del crimen vinculadas al accionar de ese personaje protagonista.

\section{El tratamiento literario de la violencia atroz}

El tratamiento de la violencia en las tres novelas comentadas obedece a convicciones diferentes e, incluso, opuestas sobre la relación entre la literatura y los hechos históricos que le sirven de referencia y sería tarea de un trabajo más amplio hacer un análisis detallado de los procedimientos textuales que cada novela despliega. Sin embargo, he destacado dos asuntos que resultan sustanciales para entender los proyectos creativos de estas novelas: la construcción de los asesinos y el tratamiento de las formas del crimen que estos despliegan.

Ahora bien, como se ha hecho evidente en el desarrollo de este trabajo, lo atroz constituye un elemento sustancial de la Violencia en el Valle del Cauca. Efectivamente, miles de personas

\footnotetext{
${ }^{19}$ Estas son otras de las valoraciones que sobre la novela de Caicedo hace Álvarez Gardeazábal en su monografía de grado: "La más popular de todas las novelas del periodo fue esta novela del vallecaucano Daniel Caicedo. La más popular por lo escueto de lo narrado, por tratar dos temas vedados para la prensa de ese entonces, la matanza de Ceylán y el atropello asesino a la Casa Liberal de Cali donde se refugiaban los exilados de las montañas" (55), "Es una obra simple y llanamente un testimonio" (56), "En fin, Viento seco (...) no logra, en forma alguna, consolidar esa novela que los dos hechos novelables cumbres del período entregaron a los escritores" (57).
} 
fueron asesinadas con una crueldad y sevicia extremas, a través de procedimientos y rituales cuya sola descripción produce horror. Los autores que se enfrentaron literariamente a este fenómeno tuvieron necesariamente que pasar por la pregunta sobre el tratamiento estético de lo atroz. Las tres novelas aquí analizadas ofrecen tres respuestas distintas.

Con la repetición y acumulación de escenas que detallan las diversas formas del crimen a través de las cuales los asesinos destruían personas, cadáveres y proyectos de futuro, Viento seco hace una inmersión profunda en dicha atrocidad. Esta se refuerza haciendo énfasis en el carácter sádico de los criminales, el deleite que el sufrimiento prolongado de la víctima les produce, su condición de monstruos. La propuesta estética de la novela consiste, entonces, en mirar de frente al monstruo y ofrecerle al lector una síntesis terrible y descarnada del fenómeno que le sirve de referencia.

Como Noche de pájaros es una novela construida sobre la experiencia de la víctima en relación con el miedo que la violencia genera, ni los asesinos ni las formas del crimen ganan protagonismo y, en consecuencia, la crueldad es una mera referencia. Los criminales son concebidos como sombras que acechan desde los "carros fantasmas" y como aves feroces que se abalanzan sobre las víctimas inermes y, por ende, no se desarrolla su sadismo ni se detallan sus prácticas criminales. La propuesta estética de la novela, en la que no parece tener cabida la atrocidad, se define por una inmersión en el personaje protagonista y una prosa de intenciones poéticas.

Cóndores no entierran todos los días privilegia la experiencia del criminal, pero no por su actuación como asesino sino por su complejidad humana. Durante una buena parte de la novela, las formas atroces del crimen a través de las cuales los asesinos, bajo las órdenes del personaje protagonista, llevaron a cabo el exterminio de sus opositores políticos se silencian y las víctimas se describen como si hubiesen sido ultimadas de manera eficiente por un limpio tiro en la nuca. Al final, aparecen referidas algunas huellas de crueldad y sevicia en los cadáveres, pero sólo como producto de la venganza personal de León María Lozano; también hacia el final el narrador nos dice que esos crímenes se comenzaron a ejecutar contra niños y mujeres, pero solo cuando el Cóndor ha perdido poder de contención sobre los asesinos. De esta manera, su propuesta estética busca superar las limitaciones de la novelística de la Violencia que le precede, en dos aspectos: la construcción de un personaje consolidado y la elusión de la atrocidad en lo atinente a los asesinatos ordenados por el personaje protagonista. 
Viento seco y Cóndores no entierran todos los días, situadas en las antípodas en cuanto al tratamiento literario de la crueldad, tuvieron una amplia acogida entre los lectores y se constituyeron, cada una en su momento, en obras muy leídas en Colombia. Fueron, además, reeditadas y reimpresas muchas veces. Sin embargo, a despecho de su éxito editorial, las valoraciones de la crítica tomaron direcciones contrarias: la novela de Álvarez Gardeazábal fue aplaudida por sus méritos literarios, a la de Caicedo se le negó cualquier valor literario. ${ }^{20}$ Noche de pájaros ni ganó el aplauso ni la condena, ni de los lectores ni de la crítica y pasó a ser una novela desconocida.

La comparación entre las propuestas ficcionales de Viento seco, Noche de pájaros y Cóndores no entierran todos los días, en relación con el tratamiento de la violencia atroz, su acogida por parte de los lectores y la disímil sanción de la crítica sobre ellas se constituyen en una constancia de la vigencia para la crítica del juicio negativo sobre la presencia de la atrocidad en el texto literario, que no es, según la sentencia de García Márquez, "el camino que llevara a la novela" (287).

Ahora bien, la crueldad es elemento sustancial de esa violencia: "No había límites a la violencia cuando se trataba de liquidar al opositor. Los medios impresos de la época de la Violencia se llenaron de fotos que hoy en día cuesta trabajo mirar, y así Colombia se convirtió en una pila de cuerpos desmembrados y mudos" (Uribe 95). Como la condición esencial de esa violencia es la atrocidad, surge la pregunta por el valor de aproximarse literariamente a esos fenómenos de violencia atroz despojándolos de su característica más definitoria: ¿Si para evitar la mirada de la Gorgona tenemos que eludir la esencia misma del fenómeno qué sentido tiene novelarlo?

Esto nos conduce de nuevo al asunto que desde hace décadas tratamos de dilucidar los escritores que nos ocupamos del asunto: ¿Cómo tratar literariamente la violencia atroz? Dado que esas prácticas atroces se han repetido en la geografía nacional y se han convertido en una constante de la violencia que padecemos los colombianos, esa pregunta es cada vez más válida y vigente. Algunos escritores siguen presuponiendo la intratabilidad del tema, otros damos respuestas más arriesgadas. Creo que es una tarea también de la crítica revisar los paradigmas desde los cuales se examina dicha literatura.

20 Examino este asunto en mi artículo: "En torno a la dimensión literaria de Viento seco". 


\section{Referencias}

Álape, Arturo. Noche de pájaros. Bogotá: Planeta, 1984. Impreso.

Álvarez Gardeazábal, Gustavo. "La novelística de la Violencia en Colombia". Monografía de grado. Cali: Universidad del Valle, 1970. Impreso.

Álvarez Gardeazábal, Gustavo. Cóndores no entierran todos los días. Bogotá: Plaza y Janés, 1997 (1972). Impreso.

Aprile Gniset, Jacques. Urbanización y violencia en el Valle. Cali: Universidad del Valle, 2017 (1980). Impreso.

Atehortúa Cruz, Adolfo León. El poder y la sangre: Las historias de Trujillo (Valle). Bogotá: Cinep-Universidad Javeriana, 1995. Impreso.

Betancourt, Darío y Martha L. García. Matones y cuadrilleros: Origen y evolución de la violencia en el occidente colombiano, 1946-1965. Bogotá: Tercer Mundo, 1990. Impreso.

Caicedo, Daniel. Viento seco. Buenos Aires: Editorial Nuestra América, 1954 (1953). Impreso.

García Márquez, Gabriel. "Dos o tres cosas sobre la novela de la violencia en Colombia". Obra Periodística. Vol. 6. Bogotá: Oveja Negra, 1983 (1959). 285-314. Impreso.

García, Antonio. "La novela realista frente al drama colombiano (prólogo-ensayo)". Viento seco. Daniel Caicedo. Buenos Aires: Editorial Nuestra América, 1954: 13-53. Impreso.

Gilard, Jacques. "Cóndores no entierran todos los días. tragedia en vez de historia". Aproximaciones a Gustavo Álvarez Gardeazábal. Raymond L. Williams. Bogotá: Plaza y Janés, 1977. 63-75. Impreso.

Guzmán Campos, Germán. La violencia en Colombia: Estudio de un proceso social. Bogotá: Tercer Mundo Editores, 1962. Impreso.

Hobsbawn, Eric J. Rebeldes primitivos: Estudio sobre las formas arcaicas de los movimientos sociales en los siglos XIX y XX. Barcelona: Ariel, 1983 (1968). Impreso.

Navia, Carmiña. "León María Lozano. Héroe-testimonio”. Poligramas 12 (1978): 95-106. Impreso.

Oquist, Paul. Violencia, conflicto y política en Colombia. Bogotá: Banco Popular, 1978. Impreso.

Osorio, Óscar. "En torno a la dimensión literaria de Viento seco". Acta Literaria 53 (2016): 111-125. Impreso.

Osorio, Óscar. "Proselitismo y violencia en Viento seco". Anales de la Literatura Hispanoamericana 48 (2019). En imprenta. 
Osorio, Óscar. "Siete estudios sobre la novela de la violencia en Colombia, una evaluación crítica y una nueva perspectiva". Poligramas 25 (julio 2006): 85-108. Impreso.

Palacios, Marco. Entre la legitimidad y la violencia. Colombia 1875-1994. Bogotá: Norma, 1995. Impreso.

Pécaut, Daniel. "Reflexiones sobre la violencia en Colombia". En: Violencia, guerra y paz. Una mirada desde las ciencias sociales. Colombia: Universidad del Valle, 2001 (1996): 2570. Impreso.

Pécaut, Daniel. Orden y violencia. Evolución sociopolítica de Colombia entre 1930 y 1953. Bogotá: Norma, 2001 (1987). Impreso.

Pineda Botero, Álvaro. La novela colombiana, 1934 - 1985. Medellín: Eafit, 2001. Impreso.

Restrepo, Laura. "Niveles de realidad en la novela de la 'violencia colombiana'”. En: Martha Cárdenas (ed.), Once ensayos sobre la Violencia. Bogotá: Cerec - Centro Gaitán, 1985 (1976): 117-169. Impreso.

Reyes, Catalina. "El gobierno de Mariano Ospina Pérez: 1946-1950”. En: Álvaro Tirado Mejía (y otros), Nueva historia de Colombia. Colombia: Planeta, 1989: 9-32. Impreso.

Sánchez, Gonzalo y Donny Merteens. Bandoleros, Gamonales y Campesinos. El caso de la Violencia en Colombia. Bogotá: El Áncora Editores, 2002 (1983). Impreso.

Uribe, María Victoria. "Los fantasmas no inquietan nunca a las cosas muertas: entre el terror y el desaliento en Colombia". Revista M3.5 (2018): 92-102. Web.

Villoria Nolla, Maite. "Cóndores no entierran todos los días. ¿Una ficcionalización de la historia colectiva?". Cuadernos de Literatura 7.13-14 (2001): 224-232. Impreso. 